O Eixo e a roda, Belo Horizonte, v.24, n.1, p. 155-167, 2015

\title{
Vetores da mestiçagem em Os tambores de São Luís (1975), de Josué Montello
}

\section{Vectors of miscegenation in the Os tambores de São Luís (1975), by Josué Montello}

Luiz Henrique Silva de Oliveira

Centro Federal de Educação Tecnológica de Minas Gerais (CEFET/MG), Belo Horizonte, Minas Gerais, Brasil. henriqueletras@yahoo.com.br

Resumo: Este trabalho pretende discutir como se configura a mestiçagem no romance Os tambores de São Luís (1975), de Josué Montello. Pretende-se demonstrar como o texto é pautado por um fim específico, que existe antes e para além do enredo. O narrador não só opera como fonte da história, mas também como o intérprete do seu significado. $\mathrm{O}$ efeito persuasivo da história passa por uma identificação virtual do leitor com o protagonista, Damião, mas também remete a outros personagens, como Barão. A miscigenação conduz no livro os valores e direções da representação do brasileiro ideal.

Palavras-chave: miscigenação; romance; Os tambores de São Luís.

Abstract: This paper discusses how to set up miscegenation in the novel Os tambores de São Luís (1975), by Josué Montello. We intend to show how the text is marked by a specific purpose, that is before and beyond the plot. The narrator, not only operates as a source of history, but also as the interpreter of its meaning. The persuasive effect of history goes through a virtual identification of the reader with the protagonist, Damião, 
but also refers to other characters like Barão. The miscegenation leads in the book values and directions of the Brazilian ideal representation. Keywords: miscegenation; novel; Os tambores de São Luís.

Recebido em 11 de março de 2015. Aprovado em 17 de julho de 2015.

Mesmo não existindo no Brasil um discurso literário genuinamente escravocrata, isto não quer dizer que não houve e ainda não haja posicionamentos etnocêntricos nas estruturações de nossas Letras. De maneira mais decisiva, nas últimas três décadas do século XIX, com o Naturalismo, até meados do XX, com o negrismo (OLIVEIRA, 2014) de Mário de Andrade, Raul Bopp e Jorge de Lima, muitos escritores brasileiros reproduziram os pressupostos da desigualdade racial inata, defendida pela "ciência" da época. Além disso, se, em outros contextos, houve uma proposta de segregação racial de modo mais explícito, como nos EUA, por exemplo, no Brasil, predominaram princípios tão funestos para o coletivo de descendentes de escravos: a mestiçagem e a democracia racial.

Anos após a eclosão do Modernismo brasileiro, o romance $O s$ tambores de São Luís (1975), de Josué Montello, utiliza como procedimento constitutivo a própria mestiçagem, entendida no livro enquanto saída étnica para o país. Trata-se de um discurso político, pedagógico, com forte componente moral, axiológico e ideológico. O texto literário em questão, de corte histórico, existe também em função da proposta defendida. Observa-se ainda que há uma "autoridade autoral" a conduzir a pretensão unívoca de sentido, o que hierarquiza valores e acaba conduzindo o leitor ao caminho da "verdade" defendida ao final do texto.

De acordo com Silvina Carrizo (2005, p. 261) a mestiçagem emerge do choque com o diferente e se estabelece a partir da biologia, alargando-se na sociedade através de artimanhas discursivas e de práticas estéticas e políticas. Atinge seu clímax ao ser proclamada como categoria identitária de uma nação ou território.

Ainda de acordo com Carrizo, em todos os casos em que a mestiçagem aparece enquanto foco de discussão, evidencia-se a 
deliberada relação entre a mestiçagem e as diversas formatações do discurso sobre o nacional praticado pelas elites e, não raro, absorvido intempestivamente pelo Estado-nação. Este, por sua vez, encobre-se com a capa da igualdade sócio-étnica, esquecendo-se, muitas vezes, de que a própria mestiçagem subentende o apagamento de diferenças, isto é, geralmente da parcela menos poderosa na balança capitalista.

E, para tratarmos da miscigenação e seus vetores no romance, vejamos como ela se manifesta nas ações de cada uma das seguintes personagens: Barão e Damião. Assim, por mais que se destaque o heroísmo negro no livro, por mais que ele traga em si cenas de resistência e pretenda travar uma representação positiva dos afrodescendentes, o texto tem a mestiçagem como sentido profundo.

Barão foi companheiro de Julião, pai do protagonista, Damião, no Quilombo. Trabalhara como escravo da temida Donana Jansen e fora vendido ao Dr. Lustosa. Barão tinha em torno de 40 anos quando aparece pela primeira vez na narrativa. Este apelido, segundo ele mesmo relata, adviera do tempo da Balaiada, quando lutara e obtivera em combate uma carta que lhe atribuíra o título de nobreza. Plástico, fanfarrão, destemido e sossegado, ele é uma das personagens mais intrigantes da narrativa, justamente pelo seu posicionamento.

Para Barão, a liberdade do cativeiro e a inserção do negro na sociedade de classes eram apenas utopias. Assim, de acordo com a personagem, a forma mais eficaz de resistência é aproveitar-se do que a casa-grande oferece de "positivo", ainda que em forma de pequenos prazeres, e ignorar o que ela oferece de negativo:

Prá encurtar a conversa: quem vier conversar comigo sobre carta de alforria está me ofendendo. Não quero saber de liberdade. Dá muito trabalho, e também muita despesa. $\mathrm{O}$ bom mesmo é ter um senhor como o meu Major - que me dá casa, comida, roupa lavada, charuto, sapato, e ainda me faz uns agrados. [...] De noite, se o sono custa a vir, porque não deixa de tirar os seus cochilos no meio das jogadas, eu vou ganhando um tostão aqui, um cruzado ali, e com isto faço meu pé de meia. (MONTELLO, 1976. p. 339)

A malandragem é inerente à personalidade de Barão. Para gozar de benefícios, ele cultivou a amizade do Major, ao ponto, inclusive, de ser tratado como membro da família. Era responsabilidade do cativo 
cuidar das chaves, dos pertences, da educação dos netos do escravocrata, fazer as compras, comandar os outros irmãos de cativeiro. E Barão o faz de maneira bastante singular: ao mesmo tempo em que usa as expensas do seu senhor para as obrigações da casa, surrupia tostões para si, o que lhe tem garantido boa quantidade de dinheiro guardada. Além disso, ao ser o responsável pela administração dos escravos, alivia deles o peso da extenuante tarefa, traçando concessões, diminuindo a jornada de trabalho, enfim, todo um conjunto de atitudes que promovem outra realidade para os escravos. Como letrado, ele ainda ensina a leitura para sujeitos da elite. Com estas estratégias, Barão consegue penetrar os círculos de poder e ganhar intimidades, dada sua simpatia também com as mulheres da elite. Foi assim com Damião, quando no Quilombo, e tem sido assim na casa do Major.

$\mathrm{Na}$ análise de Florestan Fernandes, a atitude malandra do escravo é resultado de um interesse em apenas "sair do atoleiro", "da condição de inferioridade deprimente".

\begin{abstract}
Por isso, a percepção social da realidade não se concentra na crítica dos modelos de organização do comportamento, da personalidade, das instituições sociais. Mas em sua utilidade imediata: o que esses modelos permitem conquistar socialmente, no momento, dentro da ordem social constituída, tal como ela se apresenta. (FERNANDES, 2008, p. 207)
\end{abstract}

Mesmo em situações bastante extremas, Barão evita enfrentar os infortúnios com ânimo beligerante. O bom-humor e uma aparente subserviência, regada de sorrisos, fazem com que Barão seja totalmente admirado pelo Major. E este jeito bonachão norteia a trajetória da personagem. Não que ele seja contrário à liberdade. Ele é apenas contrário à carta de alforria numa sociedade que não pensou o destino que dará aos negros libertos. Barão não é avesso ao contato sexual entre brancos e negros. Por isso, paralelamente a esta estratégia apegada à malandragem, Barão empreende outra, deveras muito engraçada: a de "emprenhar os buchos das brancas", como ele mesmo diz e, a partir deste ponto, insere na narrativa a tese da mestiçagem, cujo resultado é o apagamento do fenótipo negro. Certa vez, quando Damião fora ultrajado por Tertuliano, e relata o caso a Barão, este explica ao amigo a sua estratégia: 
- Não te aborreças comigo - suplicou o Barão, ainda a rir. Não estou rindo de ti, estou rindo do bilheteiro. Conheço ele. É o Tertuliano. Um pobre-diabo. Já passei o lápis na mulher dele. É um corno conhecido. Casou já velho com uma brancarana cheia de sardas, e tão frouxa que não pede bis. Ela gosta de preto; ele odeia. Principalmente depois que soube que eu andei com ela. Eu te vinguei adiantado, Damião. (MONTELLO, 1976, p. 365)

Barão se ri de ter "passado o lápis" na mulher de Tertuliano e em outras brancas. Ele se apega à mística da potência sexual atribuída aos negros de maneira a explorar este imaginário. Tão logo soube que a esposa do bilheteiro gostava do "cheiro de negro", Barão foi até ela, que imediatamente se viu inebriada. Inclusive, este ato de levar as mulheres brancas a cometerem adultério é também visto por Barão como estratégia de mestiçagem e branqueamento da população num contexto e época em que não havia métodos contraceptivos. Barão fazia questão de engravidar as mulheres brancas com quem se relacionava. Este ato, espalhado aos quatro cantos da cidade, acabaria por ridicularizar os maridos. Parafraseando o malandro, não deixar pistas do ato é o segredo do negócio, a não ser que esta pista seja um mulatinho, isto é, prova de que as brancas apreciam de fato a sexualidade afrodescendente em detrimento do homem branco. Atinge-se aqui a masculinidade do homem branco. Se, na sociedade, ele impera e domina, no campo da sexualidade, segundo Barão, encontra-se em inequívoca desvantagem.

- Tu estás calado demais, Damião. Que é que há contigo? Ainda não esqueceste o que te fez o corno do Tertuliano. Deixa isso comigo. Por ti, sou capaz de outro sacrifício: torno a pôr mais chifres na cabeça dele. Essa briga de preto com branco, aqui no Brasil, vai acabar mais depressa do que se pensa. E acaba devagarinho - na rede, ou na cama, conforme o gosto, ou até mesmo no chão, em cima de uma esteira. Daqui a pouco, quando se quiser ver mesmo um preto, não tem mais para ver. Está tudo desbotado. Hoje mesmo, de tardinha, papei uma branca vistosa, e acho que daí vai sair mais um mulatinho. Tomara que sim. (MONTELLO, 1976, p. 366) 
Para Barão, a mestiçagem é a saída possível para a questão do preconceito de cor. Ele defende que o mulato é o brasileiro por excelência, e, por consequência, devem ser cultivadas as relações interétnicas. Barão não defende só o branqueamento da população, mas a mulatização do negro, tal como concluirá Damião ao conhecer seu trineto. Penso que a estratégia de Barão peca por amenizar o conflito étnico e porque repete a posturas de diversos pensadores da "raça brasileira"; por outro lado, ao menos altera o vetor da mestiçagem no país. Em vez de o homem branco fecundar as mulheres negras a fim de clarear a cor da população, os homens negros vão fazê-lo, a fim de resultar o mulato. Barão inverte também o fato de a classe dominante oferecer para a economia social apenas os procriadores e as classes menos favorecidas, as geradoras e mães. O sentido de posse do corpo da mulher, típico da sociedade escravocrata, é abalado quando Barão propõe que os negros possuam as mulheres brancas. Daqui, duas consequências: em primeiro lugar, o patriarcado escravista é atacado em seu âmago e autoestima; em segundo lugar, a propriedade privada, o desejo feminino e a família, antes tão imaculados, são, com as ações de Barão, colocados em xeque.

Ainda que a postura de Barão recaia em estereótipos, como o do clareamento de parte da população brasileira como solução ao nosso problema étnico, não se pode considerar a personagem como pouco atuante e inconsciente do que faz. Digo isso porque, em determinado ponto da narrativa, Barão passa a defender a tese da viabilidade da cópula interétnica como saída para os conflitos sociais do país.

- Estou convencido que Deus fez o homem, mas foi o Diabo que lhe deu a cor. É por isso que uma cor não gosta da outra. Em nossa terra, devagar, sem pressa, a gente vai misturando todas elas. No fim, sai um tipo novo, que não se parece com nenhum outro. Já te falei nisso, e volto a falar. Já reparaste que são as sinhás-donas que têm mais raiva dos negros? E sabes por quê? Cada mulato que aparece na senzala é a prova de que uma negra, no remelexo da rede ou na mola da cama, passou para trás, com um branco, a sinhádona da casa-grande. Daí o ódio das sinhás-donas aos negros e aos mulatos. Ninguém leva isso em conta. E é isso que dá força ao braço da branca quando castiga um negro. Enquanto bate, ela se desforra. O branco, que é o pai, não pode deixar de ter o seu rabicho pelo filho bastardo, e vai- 
lhe dando a mão como pode. Daí a quantidade de mulato doutor que se vê agora a três por dois. Já a sinhá-moça, que não passou pela dor de cotovelo da sinhá-dona, tem é xodó pelo mulato. Nossa raça, meu caro Damião, nesse ponto, é mesmo privilegiada: o cheirinho que sai do corpo da gente é que é a nossa grande arma. Não há branco que resista ao bodum de uma negra. Com as brancas é a mesma coisa: o cheirinho de um preto faz muitas delas perderem a cabeça - e o resto do corpo: se assanham logo. Louvado seja Deus! E como nos apreciam! (MONTELLO, 1976, p. 366)

No âmbito do livro, a estratégia de Barão, embora irreverente, é bastante lógica, considerando a funcionalidade de sua concepção. Em primeiro lugar, conforme se vê na passagem acima, a existência de um mulato por si só cria discórdia entre o senhor e a sinhá velha, pois certo é que este esteve envolvido com uma negra. Com isso, abala-se a pressuposta submissão e confiança da sinhá em relação ao marido. Consequentemente, como se vislumbra na teoria de Barão, a mulher se vê dona de seu corpo e opta por usá-lo como quiser, inclusive trazendo para o leito um negro cativo, símbolo, no imaginário colonial, de vigor físico e sexual, conforme ensina Frantz Fanon (2008, p. 69). Esta estrutura tende a se repetir de maneira a formar um círculo contínuo responsável pela falta de rigidez de caráter da família patriarcal. Em segundo lugar, a existência de um mulato fora do casamento, segundo Barão, ofertalhe a possibilidade de ascensão social e consequente empoderamento simbólico. Se o pai, branco, tende a não abandonar à míngua o mulatinho, sinal de que ele receberá recursos financeiros, alimentação melhor do que a dos escravos, roupa, educação e, o mais importante, gozará da rede de influências políticas, sociais e econômicas do pai, de maneira a ter garantido um lugar na cena pública bastante diferente da senzala. Além disso, para quem procura figurar em espaços tradicionalmente ocupados por atores sociais brancos, a diluição do fenótipo afrodescendente acaba funcionando como um passaporte de tolerância - não de aceitação plena. Se, por um lado, a liberdade não se estende ao coletivo, esta estratégia de Barão mostra potência quando o objetivo é apenas promover abalos na estrutura social.

Em terceiro lugar, de acordo com Barão, a tese da diluição do fenótipo negro, além de ser paradoxalmente responsável pela ascensão de muitos homens de cor, seria por si só capaz de fazer com que as sinhás-moças despertassem a atenção para os mulatos. Este despertar 
de atenção retroalimentaria o referido ciclo, de modo que nosso país se tornasse, com o passar das gerações, notoriamente mestiço. Havendo a predominância de mulatos, o preconceito de cor deixaria de vigorar e a sociedade brasileira definitivamente se tornaria cordial.

Deveras, Barão acabou formando uma conexão de sentidos que é ambígua e coloca o negro em estado de heteronímia social permanente face ao branco. Entre os negros ou mulatos que sobem socialmente, avalia Florestan Fernandes (2008, p. 345), "sempre se encontra um ou outro que se beneficia dessa vinculação com brancos importantes". Fernandes denuncia que os brancos podem desempenhar papel de "padrinho" desse negro concebido fora do casamento oficial de maneira a também exercer domínio sobre a vida dele. Esse expediente de ascensão social, ou seja, via "padrinho", possui diversos inconvenientes, com destaque para o fato de que o negro ou mulato fica condicionado à pessoa que o ajudou e aos interesses e valores do protetor. Perde-se, de alguma forma, parcial ou na sua integralidade, a liberdade de agir e tomar decisões de acordo com a ordem social competitiva.

Quando disse anteriormente que o romance enquadra-se no esquema da miscigenação, referia-me não só ao branqueamento empreendido por Barão, mas fazia menção também à cena final do livro, quando Damião finalmente conhece seu trineto. Após preparo do leitor para o sentido unívoco da tese da miscigenação, anunciado ao longo da narrativa, há o ápice da proposta ideológica que preside o livro. Aliás, esta cena basicamente sustenta o romance por inteiro, pois é a única ação de fato ocorrida. Não se pode perder de vista que os quase oitenta anos ocupados pelo tempo da narrativa ocorrem justamente na rememoração de Damião.

Sua neta mais velha casara com um mulato; sua bisneta, com um branco, e ali estava seu trineto, moreninho claro, bem brasileiro. Apagara-se nele, é certo, a cor negra, de que ele, seu trisavô, tanto se orgulhava. Mas também se viera diluindo, de uma geração para outra, o ressentimento do cativeiro. (MONTELLO, 1976, p. 479)

A defesa da mestiçagem é o ponto de aproximação entre Barão e Damião. Ao conhecer seu trineto, Damião se emociona com o pequeno moreninho, bem brasileiro. Esta ação, ao final do livro, parece colocar em xeque toda a trajetória da personagem como intelectual e militante em defesa da abolição. 
A proposta de esquecimento do passado e do consequente apagamento de conflitos, metaforizados no apagamento étnico, pressuposto pelo vetor da mestiçagem, tal como tratada no livro, é colocada no desfecho. Durante quase toda a narrativa, há destaque para o vasto conjunto de lutas das quais participa Damião. Contudo, ao final, após praticamente sucumbir à inequívoca situação do negro pós-abolição, o protagonista acaba interiorizando a postura do branqueamento. Logo quando a abolição foi proclamada, os ex-escravos saíram às ruas a fim de cobrar seus senhores pelos seus infortúnios. A multidão enfrentou a tropa policial e se dirigiu ao Palácio do Governo. Lá, a pedido da multidão, Damião subiu ao palanque e desferiu um discurso pouco coerente com a trajetória de lutas empreendida por ele. Este discurso, aliás, será o elemento responsável pelo isolamento da personagem, a qual se vê sem forças e argumentos para a continuidade de seu trabalho de mediação entre o povo e o Governo.

\begin{abstract}
- Viva a Princesa Isabel, sim, porque a ela devemos a igualdade de todos os brasileiros. Não há mais senhores e escravos: há irmãos. E é em nome desse sentimento de fraternidade nacional que estou aqui, pra vos pedir que nos unamos, negros e brancos, em favor da paz. [...] Não estamos aqui para nos lançar uns contra os outros. Estamos aqui empenhados em que haja paz, em que haja concórdia, em que haja união, repelindo todos os atos e palavras que possam nos dividir! Não é a hora da guerra - é a hora da fraternidade! Não é a hora dos punhos cerrados - é a hora das mãos que se apertam! (MONTELLO, 1976, p. 472)
\end{abstract}

Curioso, porque o combatente Damião parece ter desistido de sua luta por melhores condições de vida para seus irmãos de cor justamente quando era necessário utilizar uma de suas melhores armas: o discurso. A reivindicação que se segue ao discurso de Damião não cobra a integração verdadeira do negro na sociedade de classes. Limita-se à defesa da paz social, passando por cima das desigualdades oriundas do cativeiro. Soa paradoxal o posicionamento do protagonista, pois esta era justamente a postura defendida pelos integrantes do Governo, pelos fazendeiros e pelos industriais que já começavam a se instalar no Maranhão. Damião acaba reproduzindo o próprio discurso da elite, em última análise. Esta cena não soa também como anúncio das consequências desta postura miscigenatória defendida pelo romance, a qual recai no abrandamento dos conflitos? 
A personagem parece ciente de que boa parte de suas lutas foram e ainda são em vão. Damião "abandona", portanto, a militância e se integra à vida familiar. Vai conhecer seu trineto, razão, segundo o livro, pela qual ele ainda encontra forças para viver.

Sua filha, negra, casa-se com um mulato. Sua neta casa-se com um branco. Sua bisneta casa-se também com um homem branco. Logo, o trineto é mestiço. $\mathrm{O}$ fenótipo branco total não é atingido, mas o trineto de Damião parece simbolizar o "moreno" como fenótipo ideal para o Brasil. O livro defende, portanto, logo em seu desfecho, o mestiço como brasileiro ideal:

E nisto Benigna tornou a apontar no retângulo da porta, chamando-o [Damião] agora para conhecer o Julião [seu neto].

- É clarinho - preveniu-lhe.

E quando ele [Damião] se curvou sobre o berço, muito emocionado, sentindo os olhos úmidos, ela lhe foi dizendo, enquanto erguia o candeeiro, para dar mais luz sobre a criança:

- Tem tua cara, meu filho. Até o nariz chato é teu. Olha a testa. Também é tua. E esse beicinho espichado. Tudo teu. É mais para branco que para preto: moreninho, como um bom brasileiro. (MONTELLO, 1976, p. 479)

Em minha leitura da obra, a proposta por traz das cenas de resistências, tão intensas ao longo das mais de 400 páginas do livro, é a de que o moreno étnico, cujos traços africanos pouco são visíveis, funciona como personificação de uma (não tão) nova face nacional, com seus resíduos africanos e indígenas selecionados e purificados pela assimilação ao molde europeu.

A saída conciliatória aqui é justamente a defesa da mestiçagem como elemento capaz de resolver os problemas étnicos do Brasil. Uma vez que o romance praticamente esteve afinado pela cultura do conflito em sua quase totalidade, a mediação proposta pelo projeto autoral pontua a diluição do negro como solução para os conflitos étnicos. O romance de Montello vê no mestiço o brasileiro ideal e capaz de congregar, 
justamente através de seu fenótipo, a paz social. A saída proposta pelo texto não rompe as fronteiras do racismo, já que os traços africanos e afrodescendentes dão lugar aos traços da branquitude. A saída cordial leva em conta também a pretensa passividade do negro neste processo de assimilação e apagamento. Não fosse assim, talvez o conhecimento do trineto, anunciado nas primeiras páginas do texto, não retornaria logo no desfecho, como espécie de conhecimento ou aprendizagem formal que o romance deseja.

A mestiçagem é uma proposta conciliatória, porém utópica para o Brasil. Reviveríamos propostas típicas do pensamento autoritário brasileiro em plena década de 1970? Teríamos conseguido abandonar a miscigenação proposta por Alencar, ou somente teríamos trocado os agentes sociais, sem alterar os vetores da proposta miscigenatória? Hoje, já teríamos conseguido apagar o "ressentimento do cativeiro"? O texto do escritor maranhense representa um conjunto vasto de lutas das quais participam Barão e Damião. Contudo, ao final da narrativa, após praticamente sucumbir à inequívoca situação do negro no pós-abolição, o protagonista acaba ratificando a postura da mestiçagem e, logo, do branqueamento também vividos pela personagem secundária aqui tratada.

Antes de finalizar esta reflexão, é preciso considerar que o trineto de Damião atualiza os sentidos do nascimento de Moacir, personagem de Iracema (1865), de José de Alencar. Neste ponto, o romance publicado nos anos de 1970 repete o mesmo vetor miscigenatório do romantismo: o apagamento do sujeito não-branco.

O escritor Romântico esboça um dos mais genuínos traços de construção da identidade nacional, justamente através da fusão do nativo com o português. Moacir, o filho da dor, desponta como expressão mestiça e ideal para o futuro da nação que se afirmava naquele momento. Há autores, como Hilário de Azevedo, que defendem a obra de Alencar como metonímia da formação do Brasil, tomando como base a releitura espacial e étnica que o romancista faz do país. Para o crítico, o ponto central do fenômeno literário Alencar é a criação de um estilo nacional, ou seja, a obra como expressão literária brasileira (AZEVEDO, 1979, p. 27), justamente porque a forma e os procedimentos literários sustentam um esboço de nação presente e um projeto futuro do país. A cena de nascimento de Moacir bem o diz: 
A jovem mãe, orgulhosa de tanta ventura, tomou o tenro filho nos braços e com ele arrojou-se às águas límpidas do rio. Depois suspendeu-o à teta mimosa; seus olhos então o envolviam de tristeza e amor.

- Tu és Moacir, o nascido de meu sofrimento. (ALENCAR, 1965, p. 201)

Talvez Iracema não tivesse consciência de que o sofrimento dela ainda seria sentido por diversas mães brasileiras. Ou, em nome de um racismo velado, as diferenças tivessem que ser silenciadas. A literatura aqui não é somente o espaço da fantasia ou o da fruição, mas veículo de condução de um perigoso projeto conservador que insiste em se fazer presente em nossas letras. Talvez se sentindo impotente diante do desejo conciliatório por vias do apagamento das diferenças, não tenha sobrado alternativa a não ser Iracema sair de cena como muitas mulheres em grande parte das ficções oitocentistas saíam. Eis as últimas palavras da personagem, logo ao deixar com Martin o resultado do envolvimento de ambos como síntese étnica: "recebe o filho de teu sangue. Era tempo; meus seios ingratos já não tinham alimento para dar-lhe! [...] o estame de sua flor se rompera" (ALENCAR, 1965, p. 210-211). E o romance, por sua vez, parece espelhar o pensamento autoritário brasileiro, ilustrado aqui através de Sílvio Romero:

Dentro de dois ou três séculos a fusão étnica estará talvez completa e o brasileiro mestiço bem caracterizado. Os mananciais negro e caboclo estão estancados, ao passo que a imigração portuguesa continua e a ela vieram juntar-se a italiana e a alemã. $O$ futuro povo brasileiro será uma mescla áfrico-indiana e latino-germânica. (ROMERO, 1949, p. 86)

Este futuro parece improvável se o vetor desejado for o do apagamento da diferença. Moacir, o "filho da dor", traz no rosto o problema de sua identificação mestiça. Os mulatos gerados por Barão e o trineto de Damião, idem. Alencar, Romero e Montello, portanto, parecem apontar uma saída para a nação tratar de sua identidade, ao mesmo tempo em que concedem discursivamente, uma posição satisfatória para os projetos das elites brasileiras. 


\section{Referências bibliográficas}

ALENCAR, J. Iracema. São Paulo: MEC/Instituto Nacional do Livro, 1965.

AZEVEDO, H. de. José de Alencar - sua contribuição para a expressão literária brasileira. Rio de Janeiro: Cadernos da Serra, 1979.

CARRIZO, S. "Mestiçagem". In FIGUEIREDO, Eurídice. Conceitos de literatura e cultura. Juiz de Fora/Niterói: Editora da UFJF/EDUFF, 2005. FANON, F. Pele negra, máscaras brancas. Trad. Renato da Silveira. Salvador: EDUFBA, 2008.

FERNANDES, F. A integração do negro na sociedade de classes. $5^{\mathrm{a}} \mathrm{ed}$. São Paulo: Globo, 2008.

MONTELLO, J. Os tambores de São Luís. $2^{\mathrm{a}}$ ed. Rio de Janeiro: José Olympio, 1976.

OLIVEIRA, L. H. S. Negrismo-percursos e configurações em romances brasileiros do século XX (1928-1984). Belo Horizonte: Mazza Edições, 2014.

ROMERO, S. História da literatura brasileira. $4^{\mathrm{a}}$ ed. 1 t. Rio de Janeiro: José Olympio, 1949. 
